\title{
Pineal organ of the Muscovy duck
}

\author{
KAMILA KWIECIŃSKA, MARIA HANUSZEWSKA, MARCELA PETRUSEWICZ-KOSIŃSKA
}

\author{
Department of Histology and Embryology, Faculty of Veterinary Medicine, \\ University of Warmia and Mazury in Olsztyn, Oczapowskiego Str. 13, 10-719 Olsztyn, Poland
}

\section{Kwiecińska K., Hanuszewska M., Petrusewicz-Kosińska M. Pineal organ of the Muscovy duck}

\section{Summary}

The avian pineal is a photosensory organ taking part in the organization of circadian and seasonal rhythms and playing an important role in the regulation of many behavior and physiological phenomena. The morphology of the pineal organ shows an enormous diversity. The aim of study was to investigate the histology and ultrastructure of the pineal organ in the Muscovy duck (Cairina moschata). The study was performed on 14-week-old females kept under natural lighting. The investigated pineals consisted of a wide distal part and narrow middle and proximal parts. The proximal part was attached to the diencephalon via the choroid plexus. The light microscopy showed a mixed structural form of the organ, which comprised both tubulo-follicular and solid parts. The stroma contained the lymphatic tissue, which occurred in a diffused form and as lymphoid nodules. Electron microscopy revealed the huge complexity of the parenchyma architecture, caused by the presence of several lumen-containing structures. According to their size and shape, they were classified into classical follicles, canals (diameter $>1 \mu \mathrm{m}$ ) and canaliculi (diameter $<1 \mu \mathrm{m})$. Pinealocytes were characterized by high variability of their shapes and sizes, frequently occurring partial or total reduction of the apical protrusions and presence of extremely numerous microtubules. The supporting cells constituted a prominent part of the pineal parenchyma and were represented by ependymal-like cells and astrocyte-like cells. Ependymal-like cells limited the lumen of follicles, canals and canaliculi.

Keywords: pineal organ, Muscovy duck, histology, ultrastructure

The pineal organ of vertebrates underwent essential transformation from photosensory to secretory organ during phylogeny. The result of this process is a significant diversity in the pineal morphology and physiology. However, the function of this organ remains unchanged. In all vertebrates, the pineal organ is responsible for the synthesis and secretion of melatonin in a diurnal rhythm.

Fundamental differences exist in morphology between the photosensory pineal organ of fish and amphibians and the endocrine pineal gland of mammals $(5,14,31)$. The avian pineal organ is considered as a transitional type between the photosensory organ of lower vertebrates and the endocrine gland of mammals $(7,31)$. From this follows a remarkable variability of forms of the avian pineal organ. Anatomy, histology and ultrastructure of the pineal organ in birds show important interspecies differences. However, up till now the pineal organ is a directly photosensory organ in all avian species studied. The pineal hormone, melatonin, controls daily and seasonal rhythms of many physiological processes and behavioral activities of birds including reproduction and adaptation to environmental conditions (9).
Anatomically, taking into account the proportion between the distal and proximal parts of the organ and the attachment to the intercommissural region six types of the pineal organ have been distinguished (25, $31)$. Types I, II and III include the organs composed of a conspicuous distal part and a tapering, strongly reduced proximal part, whose connection to the intercommisural region is difficult to track (type I), apparently missing (type II) or clearly visible (type III). The pineal organs of type IV are rod shaped and extend from the intercommisural region to the roof of the skull. Type $\mathrm{V}$ involves the pineal organs consisting of two separate - the proximal and distal parts, and type VI - organs limited to the proximal part. Two classifications of the avian pineal organ based on the histological structure are in use. The first classification distinguishes three basic types of construction of the pineal organ - saccular, tubulo-follicular and solid $(25,31)$. The second classification differentiates two structural forms: tubulo-follicular and solid-tubular $(10,18)$. However, intermediate and mixed forms have also been described $(10,11)$. The pineal organ also shows structural changes related to the post-hatching development of birds $(2,23)$. 
Morphologically, the avian pineal gland comprises three types of cells: pinealocytes, supporting cells and nerve cells. Among pinealocytes, there are receptor cells, rudimentary-receptor cells and secretory cells. The first type is characteristic for saccular, the second one is predominant in the tubulo-follicular and the third one protrudes in tubulo-follicular and solid forms of the pineal organ $(3,5,22-24,29,31)$. The second classification of the pinealocytes based on their location and communication with the lumen of follicle or sack distinguishes follicular and parafollicular cells (3). The population of supporting cells comprises ependymallike and astrocyte-like cells $(22,31)$. The avian pineal organ is innervated primarily by sympathetic nerve fibers (28). Furthermore, NADPH-diaphorase-positive nerve fibers and neurons (15) and some peptidergic nerve fibers (32) are also present.

The histology and ultrastructure of the pineal gland has been investigated mostly in the domestic avian species such as the chicken $(1,3,13,19)$, Japanese quail $(18,20)$, domestic goose (22) and domestic turkey (24). The obtained results demonstrated great differences, especially in histology and ultrastructure of rudimentary-receptor cells. Light and electron microscopic studies of the pineal organs in free-living birds were rarely performed. The pineal organs of birds living in the same habitat, tropical climate zone, demonstrated common features in their morphology $(10,11)$. The studies on the pineal organ of the common gull, a bird living in the natural conditions of the Baltic Sea coast, showed several unusual features, which have not been previously described in avian pinealocytes (24).

The Muscovy duck (Cairina moschata) is one of the domesticated ducks with the shortest period of domestication $(8,30)$. Wild ancestor of the duck lived in the tropical climate of Central America and Northern South America (33). It was domesticated in the pre-Columbian era by the inhabitants of rainforest. In the sixteenth century the birds were brought to Europe. Domesticated ducks can be kept in various environmental conditions; however, due to their origin, they endure better in hot and wet climates (27). The Muscovy duck has seasonal breeding and among all domesticated ducks is the one that still holds an extraordinary brooding capacity (12). The existence of nychthemeral rhythms in the sexual behavior of the Muscowy duck was also demonstrated. For the authors, researchers studying the pineal gland, the fact that despite domestication the Muscovy duck exhibits so many characteristics of wild birds is interesting. So far investigation of the above-mentioned phenomena did not include the pineal gland. Therefore, the present study was performed to describe the structure of the pineal organ of the Muscovy duck at the level of light and electron microscopy.

\section{Material and methods}

Animals and tissues. The studies were performed on 14-week-old females of the Muscovy duck $(n=12)$ purchased from a local farm, where they were reared under natural lighting conditions. The birds were anesthetized with isoflurane and killed by decapitation between 08:00 and 09:00 in July (in North-East Poland). The pineal glands with adjacent parts of the brain were immediately removed and prepared for histological $(\mathrm{n}=6)$ and ultrastructural $(n=6)$ investigations.

Histological studies. The pineal organs (with neighbouring parts of the epithalamus, the cerebrum and the cerebellum) were fixed in $4 \%$ paraformaldehyde solution, dehydrated in ethanol and embedded in paraffin. Next, they were cut in the sagittal or frontal plane into consecutive 5- $\mu \mathrm{m}$-thick sections using a a HM 340E microtome (Microm, Spain). The tissue sections were stained by the hematoxylin-eosin method using an automated multistainer ST 5020 (Leica, Germany). The slides were scanned using a MiraxDesk scanner (Carl Zeiss, Germany) and analyzed using Pannoramic Viewer 1.15.4 software (3D-Histech, Hungary).

Ultrastructural studies. Pineal organs were divided into three parts: proximal, middle and distal. Each of them was cut into several pieces, immersion fixed $\left(2 \mathrm{hrs}, 4^{\circ} \mathrm{C}\right)$ in a mixture of $1 \%$ paraformaldehyde and $2.5 \%$ glutaraldehyde in $0.2 \mathrm{M}$ phosphate buffer ( $\mathrm{pH} 7.4$ ), washed, postfixed in $2 \%$ osmium tetroxide ( $2 \mathrm{hrs}$, room temperature) and embedded in Epon 812. Semithin sections were cut from each of the blocks of tissue, stained with toluidine blue and examined in a light microscope in order to choose the places for the cutting of ultrathin sections. Ultrathin sections, stained with uranyl acetate and lead citrate, were examined in a Tecnai 12 BioTwin transmission electron microscope operated at $80 \mathrm{kV}$ (FEI USA) equipped with two digital cameras Veleta (Olympus, Japan) and Eage 4k (FEI USA).

All experimental procedures involving animals were carried out in compliance with Polish legal regulations determining the terms and methods for performing experiments on animals.

\section{Results and discussion}

Histological studies. The pineal organ of the Muscovy duck, located between the cerebrum and the cerebellum, consisted of a wide distal part and narrow middle and proximal parts. These parts were separated from each other by distinct narrowing. The superficially localized distal part was closely attached to the dura mater. The proximal part of the pineal was attached via the choroid plexus to the diencephalon. The organ length was 4 to $5 \mathrm{~mm}$ and the diameter ranged from 1 to $1.5 \mathrm{~mm}$ in the distal part and from 0.5 to 0.6 in the middle and proximal parts (Fig. 1).

The pineal organ was covered by a connective tissue capsule with numerous blood vessels, which was thicker on the rostral than on the caudal surface. The thin septa originating from the capsule penetrated inside the organ and created a delicate stroma. The differences in the pineal structure were visible in the 
proximo-distal direction of the organ. The parenchyma of the proximal and middle parts was formed by two or three elongated follicular structures with a slit lumen, arranged according to the long axis of the organ. The parenchyma of the distal part was more diverse. It was created by oval or round follicles with a lumen of dif-

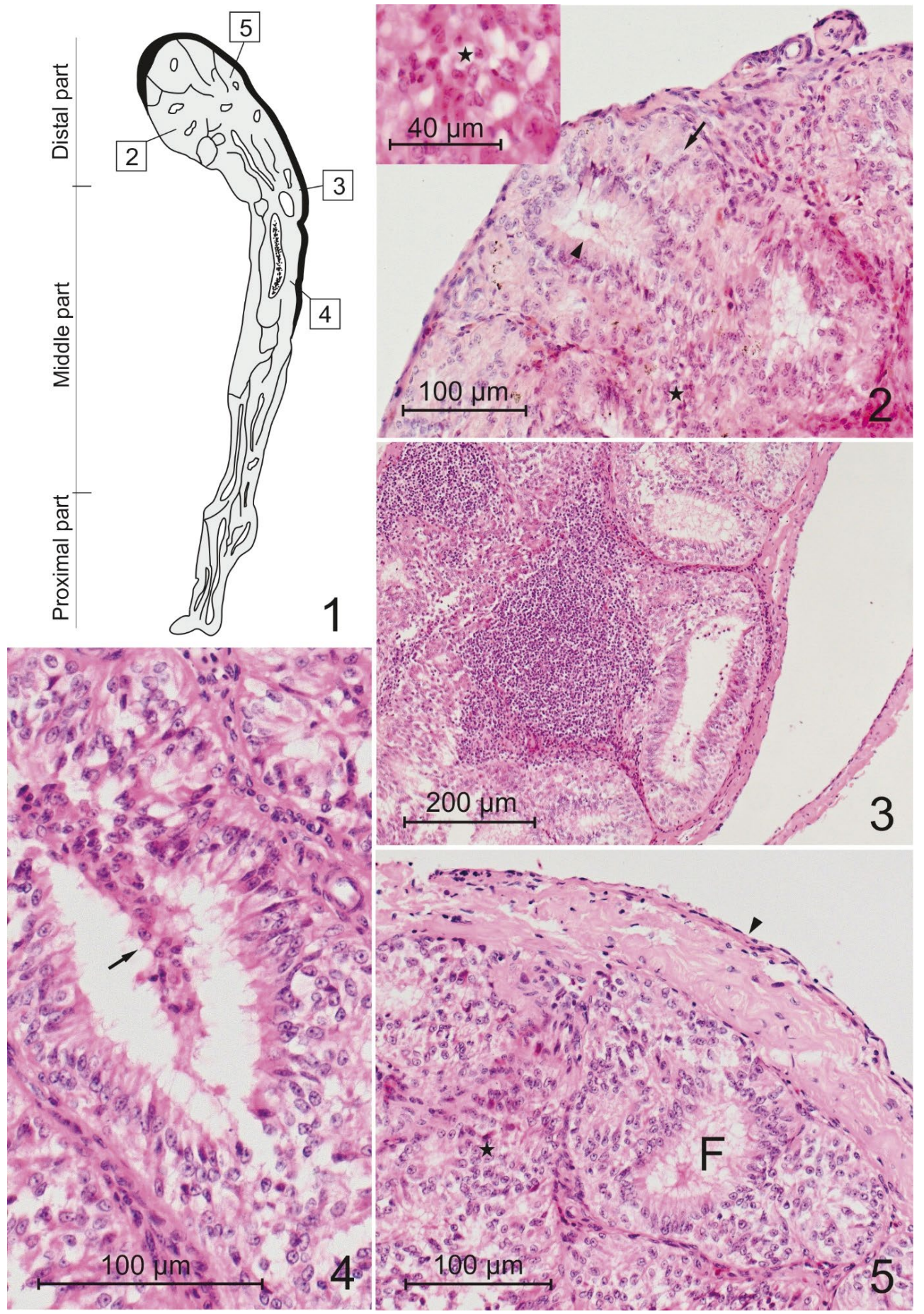

Fig. 1. Diagram illustrating the pineal organ of the Muscovy duck. Numbers 2 to 5 correspond with appropriate microphotographs

Fig. 2. Morphology of the distal part of the pineal organ. Note the follicular wall created by cylindrical cells limiting the lumen (arrow head) and oval cells (arrow) located peripherally. The lumen of the canal created by cuboidal cells (asterisk - see also inset) Fig. 3. Lymphatic cells diffusely distributed in the pineal stroma and forming lymphatic nodules

Fig. 4. Part of the elongated follicle with cluster of cells in the lumen (arrow)

Fig. 5. The distal part of the pineal organ close to the dura mater. Note the thick capsule (arrow head) as well as a solid part (asterisk) and a follicle (F) of the pineal parenchyma ferent diameter in the peripheral area, and it was solid in the central area. The solid parenchyma contained canal-like structures (Fig. 2). The cellular debris or clusters of cells were observed in the lumen of follicles (Fig. 4). Numerous small cellular prolongations were noted in the follicular lumen (Fig. 5).

The pineal parenchyma consisted of columnar cells, oval cells and cuboidal cells. The follicular wall was formed by one layer of columnar cells limiting the lumen and closely adjacent to each other, as well as usually several layers of loosely arranged oval cells located peripherally. The area of the solid parenchyma was composed by oval cells. Sometimes the cells created rosettes without a visible central lumen. The wall of the canal-like structures was created by cuboidal cells (Fig. 2 inset).

The lymphatic tissue was visible in the stroma of the pineal organ. The lymphatic cells infiltrated the connective tissue or created a lymphoid nodule. One to three nodules were noted on the longitudinal section of the pineal organ. Usually, they were located in the capsule and in the subcapsular area. In some cases, lymphoid nodules were found inside of the distal part (Fig. 3).

Ultrastructural studies. The pineal parenchyma comprised pinealocytes, supporting cells and sporadically found neurons (Figs. 6, 7, 8, $9)$. Pinealocytes were highly variable in shape, ranging from strongly elongated to oval cells. The common features of pinealocytes included the conspicuous network of microtubules, the Golgi apparatus composed by short cisterns with wide lumen, mitochondria with electron dense matrix, and moderate in number, clear and dense core vesicles. The euchromatin-rich nucleus was situated in the basal part of the cell. The majority of pinealocytes showed no stratified 

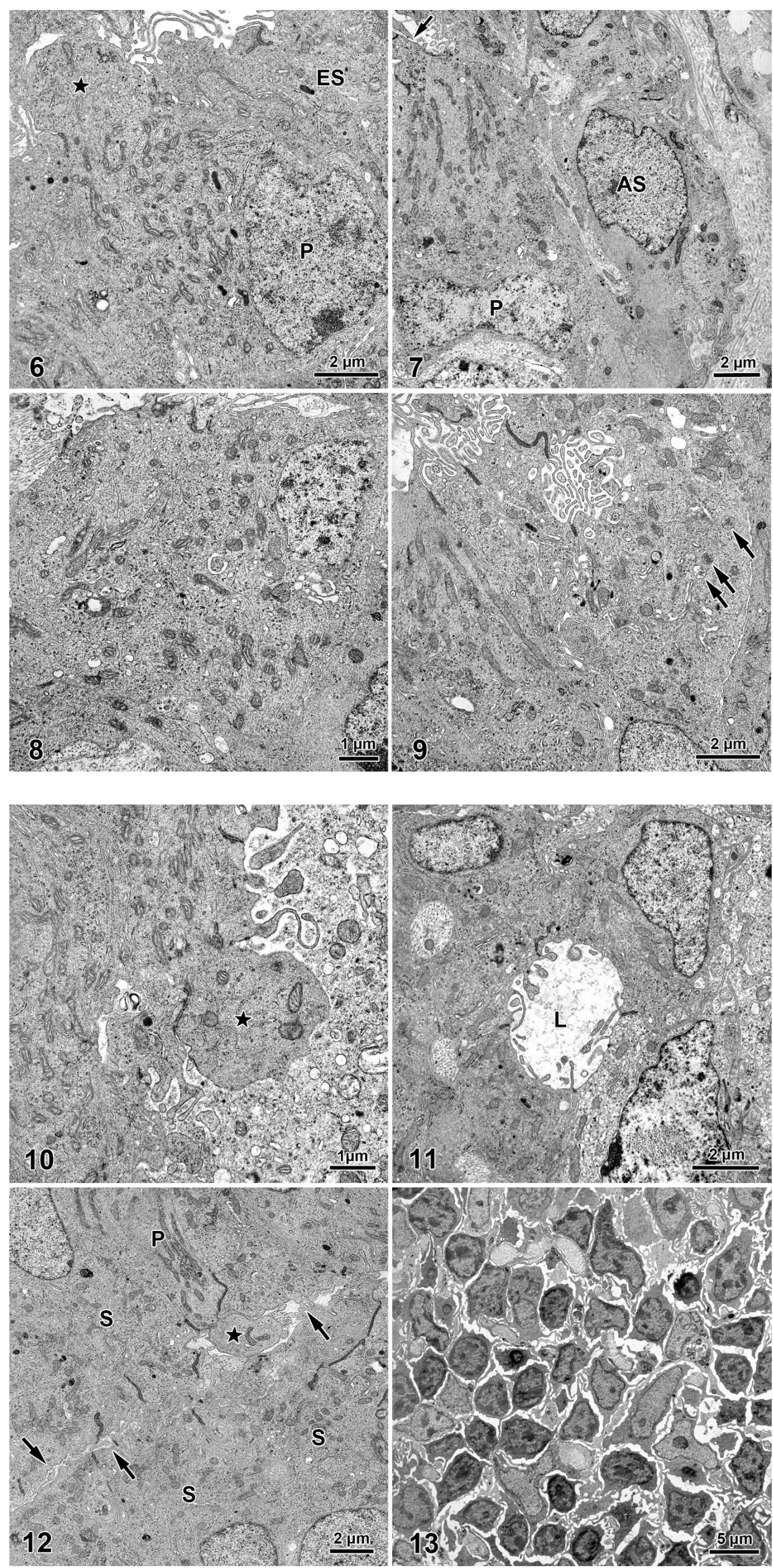
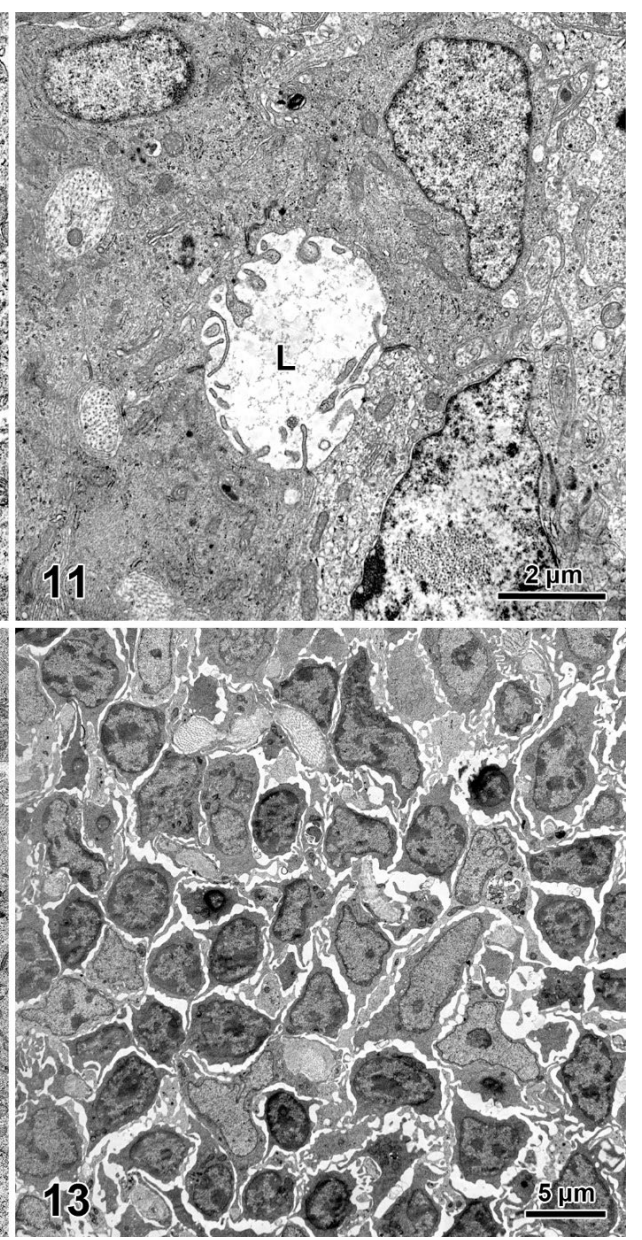

Fig. 6. Pinealocyte (P) with well-developed, bulbous apical protrusion, corresponding to the rudimentary outer segment (asterisk). Note basal localization of nucleus, mitochondria with electron dense matrix, the Golgi apparatus composed by short cisterns with wide lumen. ES - ependymal-like supporting cell

Fig. 7. Pinealocyte (P) with small apical protrusion (arrow) and astrocyte-like supporting cell (AS) close to the basement membrane. Note arrangement of mitochondria and microtubules in the apical part of pinealocyte

Fig. 8. Pinealocyte without apical protrusion. Note numerous microtubules in cytoplasm

Fig. 9. Ependymal-like supporting cell. Note microvilli on the apical surface and numerous vacuoles with flocculent material in cytoplasm (arrows)

Fig. 10. Follicle with cell debris inside. Note the well-developed, bulbous apical protrusion of pinealocyte (asterisk) Fig. 11. Canal limited by short ependymal-like supporting cells. $L$ - lumen Fig. 12. Canaliculus limited by ependymal-like supporting cells (S) and pinealocyte (P). Note the lumen (arrows) and the apical protrusion of pinealocyte (asterisk)

Fig. 13. A lymphatic nodule in the pineal stroma 
distribution of organelles, except for the presence of accumulation of mitochondria in the apical part of the cell. Microtubules run parallel in the apical and basal parts of cell and created a random network around the nucleus. Among pinealocytes having the apparent contact with the follicular lumen, there were cells with well-developed bulbous apical protrusions (corresponding to the rudimentary external segments), with very small apical protrusions and without the apical protrusions (Fig. 6, 7, 8). Pinealocytes formed one or more basal processes with endings located close to the basement membrane. The endings contained numerous clear and dense core vesicles.

The supporting cells were represented by ependymal-like cells and astrocyte-like cells (Fig. 6, 8). The ependymal-like cells limited the lumen of pineal follicles, canals and canaliculi (Fig. 10, 11, 12). They were cubic or cylindrical in shape, with euchromatinrich nucleus located in middle or apical part of cell. The characteristic patters of ependymal-like cells were: i) numerous intermediate filaments, ii) the Golgi apparatus with elongated, very flat cisterns, usually located in the apical part of the cell, iii) numerous vacuoles with flocculent material, and iv) glycogen particles. The intermediate filaments frequently created bundles in the basal part of the cell. These cells also contained electron dense core vesicles. The ependymal-like cells formed microvilli on their apical surface. The astrocyte-like cells were filled with numerous filaments and were poor in organelle. They were usually observed close to the basement membrane. Infrequently observed neurons had large euchromatin-rich nucleus and electron-lucent cytoplasm with well-developed rough endoplasmic reticulum.

The architecture of pineal parenchyma was highly complex due to the presence of several lumen-containing structures (Fig. 10, 11, 12). According to the size and shape, they were classified into classical follicles, canals (diameter $>1 \mu \mathrm{m}$ ) and canaliculi (diameter $<1 \mu \mathrm{m}$ ). The later were not noticeable using light microscopy. The cells bordering the canals and canaliculi formed the tight and adherens junctions in their apical parts. The canals and the canaliculi were limited by ependymal-like supporting cells and pinealocytes. The cell debris was frequently observed inside the follicles. Frequently, cells and cell processes located close to the basement membrane were separated each other by large, empty spaces.

The pineal stroma contained a dense network of blood vessels, bundles of myelinated and unmyelinated nerve fibers and accumulation of lymphocytes and lymphoblasts (Fig. 13). The capillary vessels surrounding the basement membrane had a continuous endothelium without fenestration.

The results of the present study have clearly indicated that the shape and location of the pineal organ in the Muscovy duck is coherent with those attributed to the fourth anatomical type of the avian pineals accord- ing to classification proposed by Quay and Renzoni (25). This type includes rod-shaped organs, extending from the intercommissural region to the roof of the skull. A characteristic feature of the pineal organ in the Muscovy duck is the presence of three, easily distinguishable parts: the distal part, the intermediate part and the proximal part.

The light microscopy showed the mixed type of the pineal parenchyma organization in the Muscovy duck. The central region of the distal part of organ has a solid structure, while the other parts have the tubulofollicular organization. The histological structure of this pineal is different from the tubulo-follicular form of the pineal organ described in the domestic turkey (24) and the domestic goose (22), and also from the solid form occurring in adult chicken (1). A similar structure of the distal part to this in the Muscovy duck was observed in the pineal organ of the common gull (23).

The follicular wall in the pineal organ of the Muscowy duck usually shows multilayer organization formed by a layer of elongated cells bordering the lumen, and several layers of oval cells, located peripherally. The elongated follicles with a narrow lumen located in the middle and proximal parts of the organ have a pseudostratified organization of their wall. A specific feature of the investigated organ was the presence of large "empty" spaces between cells in the peripheral parts of the follicles. Such a loose arrangement of the peripheral part of follicles has not been observed before. In previously studied species the peripheral part of follicle had a compact structure; for example, in the chicken (2), domestic turkey (24), domestic goose (22), and common gull (23). Another unusual aspect of the histological structure of the Muscowy duck pineal organ is the presence of the canal-like structures surrounded by cuboidal cells. Similar structures were described in the Antarctic penguin (21).

The presence of lymphoid tissue seems to be a common feature of the avian pineal organ, nevertheless with prominent interspecies variability. The accumulation of lymphocytes in the form of a lymphatic nodule was noted in the domestic chicken $(1,2)$ and the common sandpiper (31), but not in the domestic goose (22) and the common gull (24). In the domestic turkey, a moderate number of lymphatic cells within the connective tissue septa and sporadically lymphatic nodules were found (24). The term pineal associated lymphatic tissue (PALT) has been proposed based on similarities in cellular composition with mucosaassociated lymphatic tissue in the chicken (17). In the present study, both diffused and accumulated lymphatic cells were observed in the pineal stroma. The degree of lymphocyte infiltration in the examined organs suggests the physiological importance of this phenomenon. The existing research showed that pineal immune cells can play an important compensatory role 
in age-related atrophy of the thymus $(4,16)$. Day-night variations described in the organization of PALT in the chicken point to specific neuro-immune interactions in this part of the brain (17).

The ultrastructural study confirmed the results of histological investigations concerning the complicated structure of the pineal parenchyma. There are three types of structures possessing lumen: (i) the follicular structures, (ii) canals surrounded by cuboidal cells and (iii) canaliculi with a very small diameter. The first structures are typical for most of the pineal organs in birds $(22-24,31)$. In contrast, canals and canaliculi were infrequently reported in the pineal organs of birds investigated so far. Canaliculi with a diameter less than one $\mu \mathrm{m}$ were noted in the Antarctic penguin (21). Getting to know the relationships between these structures is very difficult. The authors assumed that the observed structures represented the consecutive branches of the pineal lumen. However, the explanation of detailed interrelations between these structures requires further studies including 3D reconstructions based on serial ultrathin sections.

The parenchymal cells of the avian pineal organ belong to pinealocytes, supporting and nerve cells. Pinealocytes have been classified into three main types according to Vollrath (31). The first one includes pinealocytes of the receptor type possessing an outer segment with lamellar whorls. The second one is represented by rudimentary-receptor pinealocytes with a reduced outer segment without lamellar whorls. These two types of pinealocytes border the pineal lumen. Pinealocytes of the third type, called secretory, apparently do not have any connections with the lumen of the pineal organ. The last two types of pinealocytes exist in most of the examined birds having the pineal organ of tubule-follicular or solid-tubular form. The rudimentary-receptor type of pinealocytes with an outer segment in the form of an apical prolongation of different shapes and sizes was characterized in details in the common gull (23), the domestic goose (22) and the domestic turkey (24). These cells usually showed a stratified distribution of organelles and a nucleus situated basally. The sensory cilium containing a system of nine pairs of peripheral microtubules and devoid of a central one was usually noted in the apical part of rudimentary-receptor pinealocytes. The secretory pinealocytes in the pineal organs of these species formed a population of cells with centrally localized nuclei and randomly arranged organelles. Usually, they possessed several small processes penetrating between adjacent cells.

The findings of the present study showed that pinealocytes in the Muscovy duck are characterized by a high variability of their shapes and sizes, frequently almost total reduction of their outer segments and extremely numerous microtubules. The population of rudimentary-receptor pinealocytes in this species comprises both prominently elongated cells and very short cells. A majority of these cells lack the apical protrusion or possess a very small apical protrusion. The microtubules are spread out around the nucleus and form parallel arrangement in the apical part of the cell and in the basal processes. The pinealocytes do not show the stratified distribution of organelles, except for the accumulation of mitochondria in the apical part of the cell. The complicated organization of the pineal organ in the Muscovy duck, particularly the presence of canals and canaliculi, does not make it clear if there are pinealocytes which are not in contact with the pineal lumen. As a result, we cannot unambiguously state the presence of secretory pinealocytes in the Muscovy duck pineal organ.

Ultrastructural analysis of the Muscovy duck pineal organ exhibited the presence of numerous both clear and dense-core vesicles. They were observed in pinealocytes and occasionally in ependymal-like cells. The vesicles of both types are the common feature of rudimentary-receptor and secretory pinealocytes in the avian pineal organ $(10,22,23)$. It is believed that they are secretory in nature $(7,10)$. The number of these structures differs considerably between the pineal organs of individual species of birds. A large number of dense-core and clear vesicles was noted in Athene brama and Euroloncha punchulata (10). Numerous dense core vesicles and few clear vesicles were observed in the domestic goose (22), while in the chicken and the common gull the presence of numerous clear vesicles and few dense core vesicles was reported $(3,23)$.

The supporting cells constituted an important part of the pineal parenchyma in the Muscovy duck and were represented by ependymal-like cells and astrocyte-like cells. Ependymal-like cells limited the lumen of tubulo-follicular structures, canals and canaliculi. These cells had a significantly greater share in the pineal organ architecture compared to the other examined bird species. In the domestic goose, common gull and Antarctic penguin (21-23), they were found in moderate numbers and together with rudimentaryreceptor pinealocytes limited the follicular lumen. The morphology of ependymal-like cells in the Muscovy duck suggests their intensive metabolic and secretory activity. These cells contain vacuoles with flocculent material and dense core vesicles. The morphology and arrangement of astrocyte-like supporting cells in the Muscovy duck do not show differences compared to the pineal organs of other birds $(7,22)$.

Summing up, the findings of our study showed exceptional morphological features of the pineal organ in the Muscovy duck. The most intriguing is the presence of canals and canaliculi as well as a large participation of ependymal-like supporting cells in the formation of the pineal parenchyma. The exact explanation of the pineal structure in this species requires further research based on 3D techniques. 


\section{References}

1. Boya J., Calvo J.: Evolution and nature of the dense bodies in the chicken pinealocytes. Acta Anat. (Basel) 1979, 104, 61-71.

2. Boya J., Calvo J.: Post-hatching evolution of the pineal gland of the chicken. Acta Anat. (Basel) 1978, 101, 1-9.

3. Boya J., Calvo J.: Ultrastructural study of the post-hatching evolution of the pineal gland of the chicken (Gallus gallus). Acta Anat. (Basel) 1980, 107, 143-168

4. Cogburn L. A., Glick B.: Functional lymphocytes in the chicken pineal gland J. Immunol. 1983, 130, 2109-2112.

5. Collin J. P., Falcon J., Voisin P., Brisson P.: The Pineal Organ: Ontogenic differentiation of photoreceptor cells and pinealocytes, [in:] Gupta D., Reiter R. J. (ed.): The Pineal Gland During Development: from Fetus to Adult. Croom Helm, London \& Sydney 1986, p. 14-30.

6. Eakin R. M.: The Third Eye. University of California Press, Berkeley 1973.

7. Fejer Z., Rohlich P., Szel A., David C., Zadori A., Manzano M. J., Vigh B.: Comparative ultrastructure and cytochemistry of the avian pineal organ. Microsc. Res. Tech. 2001, 53, 12-24.

8. Gade D. W.: Moscovy duck, [in:] Kiple K. F., Ornelas K. C. (ed.): The Cambridge World History of Food. Cambridge University Press, Cambridge 2000, p. 559-560.

9. Gwinner E.: Circannual rhythms in birds. Curr. Opin. Neuro-biol. 2003, 13, 770-778.

10. Haldar C., Bishnupuri K. S.: Comparative view of the pineal morphology of nocturnal and diurnal birds of tropical origin. Microsc. Res. Tech. 2001, 53, 25-32.

11. Haldar C., Guchhait P.: Pineal gland of a nocturnal bird, Indian spotted owlet, Athene brama: morphological and endocrine observations. J. Exp. Zool. 2000, 287, 145-150.

12. Harun M. A., Draisma G., Frankeena K., Veeneklaas R. J., Van Kampen M.: Breeding biology of muscovy duck (Cairina moschata) under natural incubation: the use of the weibull function and a beta-binomial model to predict nest hatchability J. Theor. Biol. 1999, 198, 89-99.

13. Jove M., Cobos P., Torrente M., Gilabert R., Piera V.: Embryonic development of pineal gland vesicles: a morphological and morphometrical study in chick embryos. Eur. J. Morphol. 1999, 37, 29-35.

14. Klein D. C., Bailey M. J., Carter D. A., Kim J. S., Shi Q., Ho A. K., Chik C. L., Gaildrat P., Morin F., Ganguly S., Rath M. F., Møller M., Sugden D., Rangel Z. G., Munson P. J., Weller J. L., Coon S. L.: Pineal function: impact of microarray analysis. Mol. Cell. Endocrinol. 2010, 314, 170-183.

15. Lewczuk B., Nowicki M., Brzozowski W., Przybylska-Gornowicz B.: Distribution of NADPH-diaphorase activity in the pineal gland of the turkey. Folia Histochem. Cytobiol. 2002, 40, 145-146.

16. Linkova N. S., Khavinson V. Kh., Chalisova N. I., Katanugina A. S., Koncevaya $E$. A.: Peptidegic stimulation of differentiation of pineal immune cells. Bull. Exp. Biol. Med. 2011, 152, 124-127.

17. Mosenson J. A., McNulty J. A.: Characterization of lymphocyte subsets over a 24-hour period in Pineal-Associated Lymphoid Tissue (PALT) in the chicken. BMC Immunol. 2006, 11, 7:1, DOI: 10.1186/1471-2172-7-1

18. Ohshima K., Hiramatsu K.: Ultrastructural study of post-hatching development in the pineal gland of the Japanese quail. J. Vet. Med. Sci. 1993, 55, 945-950.

19. Ohshima K., Matsuo S.: Functional morphology of the pineal gland in young chickens. Anat. Anz. 1984, 156, 407-418.

20. Ohshima K., Matsuo S.: Photosensory elements in the pineal gland of the Japanese quail, with special reference to the paraboloid. Anat. Anz. 1991, 172, 247-255

21. Piezzi R. S., Gutierrez L. S.: Electron Microscopic Studies on the Pineal Organ of the Antarctic Penguin, (Pygoscelis papua). Cell Tiss. Res. 1975, 164, 559-570

22. Prusik M., Lewczuk B., Nowicki M., Przybylska-Gornowicz B.: Histology and ultrastructure of the pineal organ in the domestic goose. Histol. Histopathol 2006, 21, 1075-1090.

23. Przybylska-Gornowicz B., Lewczuk B., Prusik M., Kalicki M., Ziolkowska N.: Morphological Studies of the Pineal Gland in the Common Gull (Larus canus) Reveal Uncommon Features of Pinealocytes. Anat. Rec. 2012, 295, 673-685.

24. Przybylska-Gornowicz B., Lewczuk B., Prusik M., Nowicki M.: Post-hatching development of the turkey pineal organ: Histological and immunohistochemical studies. Neuroendocrinol. Lett. 2005, 26, 383-392.

25. Quay W. B., Renzoni A.: The diencephalic relations and variably bipartite structure of the avian pineal complex. Riv. Biol. 1967, 60, 9-75.
26. Rath M. F., Rohde1 K., Klein D. C., Møller M.: Homeobox genes in the rodent pineal gland: roles in development and phenotype maintenance. Neurochem. Res. 2013, 38, 1100-1112.

27. Ruskin F. R., Dafforn M., Engquist M. J., Mouzon E., Vkeyens J. (ed): Microlivestock: Little-Known Small Animals with a Promising Economic Future. National Academy Press, Washington 1991, p. 125-135.

28. Sato T., Wake K., Kramm C., Korf H. W.: Chicken pineal organs during posthatching development: photoreceptor-specific characteristics and innervation, [in:] Gupta D., Wollmann A., Ranke M. B. (ed.): Neuroendocrinology: Quid Novi, Brain Research Promotion. Tübingen, London 1990, p. 191-200.

29. Singh N. S., Dixit A. S.: Participation of endogenous circadian rhythm in photoperiodic time measurement during ovarian responses of the subtropical tree sparrow, Passer montanus. Indian J. Exp. Biol. 2014, 52, 496-503.

30. Stahl P. W., Mue M. C., Delgado-Espinoza F.: New evidence for pre-Columbian Muscovy Duck Cairina moschata from Ecuador. Ibis 2006, 148, 657-663.

31. Vollrath L.: The pineal organ, [in:] Handbuch der mikroskopischen Anatomie des Menschen VI/7. Springer-Verlag, Berlin 1981.

32. Wagner G., Herman A., Brandstaetter R.: Modulation of pineal activity in birds, [in:] Morgan P. J., O'Reilly L., White A., Hazlerigg D. (ed.): Book of Abstr. IX ${ }^{\text {th }}$ Symposium of European Pineal and Biological Rhythm Society, Scotland. Aberdeen 2002, p. 76.

33. Zeng T., Zhang L., Li J., Wang D., Tian Y., Lu L.: De novo assembly and characterization of Muscovy duck liver transcriptome and analysis of differentially regulated genes in response to heat stress. Cell Stress Chaperones 2015, 20, 483-493

Corresponding author: vet. surg. Kamila Kwiecińska, Department of Histology and Embryology, Faculty of Veterinary Medicine, University of Warmia and Mazury in Olsztyn, Oczapowskiego St. 13, 10-719 Olsztyn, Poland; e-mail: kamila.kwiecinska91@gmail.com 